\title{
Prediction of bulk milk fatty acid composition based on farming practices collected through on-farm surveys
}

\author{
M. Coppa, ${ }^{*}+\ddagger^{1}$ A. Ferlay, ${ }^{*} \dagger$ C. Chassaing, ${ }^{*} \dagger$ C. Agabriel, ${ }^{*} \dagger$ F. Glasser, ${ }^{*} \dagger$ Y. Chilliard, ${ }^{\dagger} \dagger$ G. Borreani, $\ddagger$ \\ R. Barcarolo,§ T. Baars,\# D. Kusche,Il O. M. Harstad,ף J. Verbič,** J. Golecký,†† and B. Martin*† \\ *INRA, UMR 1213 Herbivores, F-63122 Saint-Genès-Champanelle, France \\ †Clermont Université, VetAgro Sup, UMR Herbivores, BP 10448, F-63000 Clermont-Ferrand, France \\ fUniversità di Torino, Dipartimento di Scienze Agrarie, Forestali e Alimentari, Via L. da Vinci 44, 10095, Grugliasco, Italy \\ §Veneto Agricoltura - Ist. Qualità e Tecnologie Agroalimentari, Via S. Germano 74, I-36016, Thiene (VI), Italy \\ \#Research Institute of Organic Agriculture (FiBL), Ackerstrasse, 5070 Frick, Switzerland \\ IIKassel University, Faculty of Organic Agricultural Sciences, Nordbahnhofsstrasse 1, 37213 Witzenhausen, Germany \\ đNorwegian University of Life Sciences, Dep. Animal and Aquacultural Sciences, Arboretveien 6, 1430 Ås, Norway \\ ${ }^{* *}$ Agricultural Institute of Slovenia, Hacquetova 17, SI-1000 Ljubljana, Slovenia \\ ††Plant Production Research Center (PPRC) - Grassland and Mountain Agriculture Research Institute (GMARI), \\ Mladeznicka 36, 97421 Banska Bystrica, Slovakia
}

ABSTRACT

The aim of this study was to predict the fatty acid (FA) composition of bulk milk using data describing farming practices collected via on-farm surveys. The FA composition of 1,248 bulk cow milk samples and the related farming practices were collected from 20 experiments led in 10 different European countries at $44^{\circ} \mathrm{N}$ to $60^{\circ} \mathrm{N}$ latitude and sea level to $2,000 \mathrm{~m}$ altitude. Farming practice-based FA predictions [coefficient of determination $\left(\mathrm{R}^{2}\right)>0.50$ ] were good for C16:0, C17:0, saturated FA, polyunsaturated FA, and odd-chain FA, and very good $\left(\mathrm{R}^{2} \geq 0.60\right)$ for trans-11 C18:1, trans-10 + trans-11 C18:1, cis-9,trans-11 conjugated linoleic acid, total trans FA, C18:3n-3, n-6:n-3 ratio, and branched-chain FA. Fatty acids were predicted by cow diet composition and by the altitude at which milk was produced, whereas animal-related factors (i.e., lactation stage, breed, milk yield, and proportion of primiparous cows in the herd) were not significant in any of the models. Proportion of fresh herbage in the cow diet was the main predictor, with the highest effect in almost all FA models. However, models built solely on conserved forage-derived samples gave good predictions for odd-chain FA, branched-chain FA, trans-10 C18:1 and C18:3n-3 ( $\mathrm{R}^{2} \geq 0.46,0.54,0.52$, and 0.70 , respectively). These prediction models could offer farmers a valuable tool to help improve the nutritional quality of the milk they produce.

Key words: bulk milk, fatty acid, farming practices, prediction model

Received November 14, 2012.

Accepted March 22, 2013.

${ }^{1}$ Corresponding author: mauro.coppa@unito.it

\section{INTRODUCTION}

Dairy product consumption in Europe is about 92.9 $\mathrm{kg} /$ capita per year (FAO, 2012). Research has made huge strides forward on the effect of FA intake on human health issues such as cardiovascular disease, obesity, and metabolic syndrome (Givens, 2010; Kratz et al., 2013). The World Health Organization (2008) recommends reducing SFA intake and increasing PUFA intake. The risk of cardiovascular disease factors was found to be lower after the consumption of dairy products rich in n-3 long-chain FA (Dawczynski et al., 2010).

Decades of research have highlighted several factors affecting milk FA profile, in particular cow diet, breed, lactation stage, animal health, and altitude (Griinari et al., 1998; Dewhurst et al., 2006; Elgersma et al., 2006). Cow diet composition is the key factor (Palmquist et al., 1993). Increasing forage-to-concentrate ratio in cow diet increased milk PUFA and n-3 FA proportions and decreased SFA proportion (Dewhurst et al., 2006). Feeding cows fresh herbage greatly enhances these trends, and also increases milk trans-11 C18:1, cis-9,trans-11 conjugated linoleic acid (CLA), and C18:3n-3 proportions, reaching a highly favorable FA profile for human health (Chilliard et al., 2007). The C18:3n-3 can also be increased by supplementing cows with linseed, but the associated increase in trans C18:1 isomers, particularly trans-10 C18:1, results in a less-favorable FA profile for human health (Dewhurst et al., 2006; Chilliard et al., 2007). An increase in trans-10 C18:1 instead of trans-11 C18:1 has also been observed when cows are fed starch-rich diets based on concentrates and corn silages (Griinari et al., 1998). These diets also increased milk C18:2n-6 and total n-6 FA proportions (Griinari et al., 1998). 
In agreement with the World Health Organization (2008) recommendations on FA consumption for human nutrition, several dairy companies in various European Union (EU) countries (including France, Belgium, and the Netherlands, among others) apply a price premium for cow milk rich in health-promoting FA (i.e., n-3 and PUFA). Thus, farmers need to recover information on the expected FA profile of their milk to identify management strategies to increase the proportion of health-promoting FA in milk fat and consequently increase their income. However, the majority of studies investigating the effect of diet and animal-related factors on milk FA profile were controlled trials (i.e., Leiber et al., 2005; Ferlay et al., 2006; Colman et al., 2010), analyzing individual milk or testing diets not always reflecting common practice in commercial farms (i.e., extreme amounts of concentrate or lipid supplements), or applying measurements of farming practices not suitable on farm. This is also the case for milk FA prediction models reported in the literature. Glasser et al. (2008) predicted the main milk FA proportions focusing only on diets supplemented with different forms of oilseed. Sterk et al. (2011) predicted milk FA composition according to grass silage/corn silage proportion, forage:concentrate ratio and crushed linseed supplementation. Moate et al. (2008) developed FA prediction models for long-chain FA using intestinal FA flow and absorption and cow diet composition (fresh herbage vs. TMR only). To our knowledge, no model has yet attempted to predict FA composition of bulk milk from commercial farms, based on simple farm practice data collected on farm.

Farming practices vary widely according to country and agronomical context, but most of the literature tends to operate at tight territorial scale. Collecting data from a wide territory makes it possible to explore a broad range of farming practices and, thus, of FA profiles in commercial milk. The aim of this work was to predict the FA composition of bulk milk based on farming practices collected via on-farm surveys in different EU countries.

\section{MATERIALS AND METHODS}

\section{Data Collection}

The FA profiles of 1,248 bulk cow milk or cheese samples and their related farming practices were compiled from a selection of 20 published or unpublished studies carried out from 2000 to 2010 in 10 different EU countries: France (650 samples), Germany (157 samples), Italy (152 samples), Norway (104 samples), Slovakia (100 samples), Slovenia (75 samples), Czech Republic (3 samples), Denmark (3 samples), Sweden (2 samples), and the Netherlands (2 samples). As the cheesemaking process does not affect milk FA profile (Lucas et al., 2006b; Revello Chion et al., 2010b), cheese FA composition data were included in the dataset and considered equivalent to the bulk milk from which they derived. Table 1 details and references the studies included in the dataset. The majority of experiments were conducted on farm and included milk collected on commercial farms at between $44^{\circ} \mathrm{N}$ to $60^{\circ} \mathrm{N}$ latitude, from sea level to 2,000-m altitude, from 13 different cow breeds and in all seasons. For the experiments carried out in controlled conditions, only bulk milks derived from diets routinely found in commercial farms were considered. Concerning published experiments, the original FA profiles and farming practices data (given directly by the authors) was used instead of the published means per dietary treatment.

\section{Farming Practices}

Data on farming practices, collected at each milk sampling via on-farm surveys according to Agabriel et al. (2007), included herd characteristics (number of cows, breed, milk yield, DIM, and proportion of primiparous cows), diet composition of lactating cows, and altitude of the farm (or grazed plots). Special attention was paid to forage source (corn or grass) and, within grasses, to conservation method and utilization (fresh herbage, hay, or silage). During surveys led at each milk sampling, the quantities of the different feedstuffs [grass silage (GS), hay $(\mathbf{H})$, corn silage (CS), and concentrates (C)] given to lactating cows were estimated directly by the farmers. The animal maintenance requirements and energy value of each feedstuff were estimated according to Institut National de la Recherche Agronomique (INRA) tables (Faverdin et al., 2007). Depending on the farming practices data available, fresh herbage intake at pasture was estimated either (1) by the difference between the energy requirements of the herd and the energy provided by the known quantities of feeds offered in the diet, working to the hypothesis that energy balance was null, or (2) by the difference between the potential intake capacity of the herd and the rumen fill of the known quantities of feeds offered in the diet. Cow breed data were expressed as proportion of each breed in the herd, whereas animal feed was described as proportion of each feedstuff in the cow diet on a DM basis.

\section{FA Composition}

The milk and cheeses included were FA profiled by 5 different laboratories over the 2001-to-2010 period, using gas-chromatographic methods. References of analytical methods used are reported in Table 1. 
Table 1. Characteristics of the 20 experiments composing the dataset

\begin{tabular}{llrlll}
\hline Experiment & Year & $\mathrm{n}$ & Dairy product & Analytical methods & Reference \\
\hline 1 & 2007 & 379 & Tank milk & Loor et al. (2005) & B. Martin, unpublished data \\
2 & 2005 & 307 & Cheese & Loor et al. (2005) & Lucas et al. (2006a) \\
3 & 2004 & 50 Tank milk & Loor et al. (2005) & Ferlay et al. (2008) \\
4 & 2009 & 9 & Bulk milk & Loor et al. (2005) & Coppa et al. (2011b) \\
5 & 2008 & 27 & Bulk milk & Loor et al. (2005) & Coppa et al. (2011a) \\
6 & 2006 & 11 & Bulk milk & Loor et al. (2005) & Tornambé et al. (2010a) \\
7 & 2003 & 11 & Bulk milk & Loor et al. (2005) & Tornambé et al. (2010b) \\
8 & 2007 & 12 & Bulk milk & Loor et al. (2005) & Bartin, unpublished data \\
9 & 2001 & 20 & Cheese & Loor et al. (2005) & B. Martin, unpublished data \\
10 & 2000 & 6 & Bulk milk & Loor et al. (2005) & Ferlay et al., (2006) \\
11 & 2009 & 25 & Bulk milk & Loor et al. (2005) & A. Ferlay, unpublished data \\
12 & 2007 & 72 & Bulk milk & Loor et al. (2005) & A. Ferlay, unpublished data \\
13 & 2009 & 36 & Bulk milk & De Noni and Battelli (2008) & Revello Chion et al. (2012) \\
14 & 2006 & 8 & Bulk milk & Revello Chion et al. (2010b) & Revello Chion et al. (2010a) \\
15 & 2004 & 23 & Bulk milk & Revello Chion et al. (2010b) & Revello Chion et al. (2010b) \\
16 & 2003 & 18 & Bulk milk & Revello Chion et al. (2010b) & G. Borreani, unpublished data \\
17 & 2010 & 8 & Bulk milk & Moioli et al. (2012) & G. Borreani, unpublished data \\
18 & 2010 & 58 & Bulk milk & EN ISO 5509:2000 (ISO, 2000) & R. Barcarolo, unpublished data \\
19 & $2008 / 2009$ & 142 & Bulk milk & Kusche et al. (2010) & Kusche et al. (2010) and D. Kusche, unpublished data \\
20 & 2009 & 26 & Bulk milk & Kusche et al. (2010) & T. Baars, unpublished data \\
\hline
\end{tabular}

Due to the heterogeneity among experiments in the detailed FA identification, a simplified FA profile was selected with the aim of finding a balance between the number of FA studied and the number of samples for which FA proportions were reported. Separate proportions of trans-10 C18:1 and trans-11 C18:1 were only reported in a few experiments, and so separate calibration is based on a smaller sample set (738 samples instead of 1,248). As with most gas-chromatographic methods these 2 isomers were not separated; when only trans-11 C18:1 was reported, it was taken as the sum of trans-10 + trans-11 C18:1, and models on their sum were developed, based on a larger number of samples. Similarly, cis-9 C18:1 was assumed as the sum of cis-9 + trans-13 C18:1. When proportions of trans -4 , trans-5, trans-6/-7/-8, trans-9, and trans-12 C18:1 were determined, they were recalculated as the sum of other trans C18:1 isomers. The same calculation was applied for cis-1, cis-12, cis-13, cis-14, and cis-15 C18:1, reported as the sum of other cis C18:1 isomers. In some experiments, especially older ones, only the cis-9,trans-11 CLA was separated from the sum of C18:2 isomers. As some FA were not identified in several samples, especially in the older trials, the detail of the sum of SFA, MUFA, PUFA, odd-chain FA (OCFA), branched-chain FA (BCFA), and n-3 and n-6 FA is given. The sum of SFA pooled C4:0, C6:0, C8:0, C10:0, C12:0, C14:0, C16:0, and C18:0. The sum of MUFA pooled cis-9 C10:1; cis-9 C12:1; cis-9 C14:1; cis-9 C16:1; cis-9 C17:1; and trans-6/-7/-8, trans- 9 , trans- $10+$ trans- 11 , cis- $9+$ trans-13, cis-11, cis-12, cis-13, cis-14, and cis-15 C18:1; and the sum of PUFA pooled cis-9,trans-11 CLA; cis9,trans-13, cis-9,trans-14, cis-9,trans-12, cis-9,trans-16, trans-9,cis-12, trans-11,cis-15, and cis-9,cis-15 C18:2;
C18:2n-6; C18:3n-3; C20:2n-6; C20:3n-6; C20:4n-6; and C20:5n-3. The sum of OCFA included C7:0, C9:0, C11:0, C15:0, C17:0, and cis-9 C17:1, whereas the sum of BCFA pooled iso $\mathrm{C} 14: 0$, iso $\mathrm{C} 15: 0$, anteiso $\mathrm{C} 15: 0$, iso $\mathrm{C} 16: 0$, iso $\mathrm{C} 17: 0$, anteiso $\mathrm{C} 17: 0$, and iso $\mathrm{C} 18: 0$. The sum of trans FA pooled trans-6/-7/-8, trans- 9 , trans- 10 + trans-11, and trans-12 C18:1, and cis-9,trans-11 and trans-11,trans-13 CLA. The sum of n-3 FA pooled C18:3n-3, C20:3n-3, C20:5n-3, and C22:5n-3, whereas the sum of n- 6 FA pooled C18:2n-6, C18:3n-6, C20:2n-6, C20:3n-6, and C20:4n-6. If at least one of the FA composing the sum was missing in a sample, the sum was considered as missing.

\section{Statistical Models for Milk FA Prediction}

Statistics were performed with Minitab 14.1 software (Minitab Inc., State College, PA). Data on FA profiles were initially explored using univariate descriptive analysis and graphing of variables. Data were examined for outliers. For each FA, values lower or higher at the 1.5 interquartile distance than the first or third quartiles were considered outliers. Thereafter, the samples were divided into 2 sets: calibration set and validation set. The calibration set (about $80 \%$ of the samples, corresponding to $999 \mathrm{FA}$ profiles) was used to calibrate the models, whereas the remaining randomly selected $20 \%$ of samples (249 FA profiles) in the dataset were used to perform external validation of the models.

To develop a prediction of FA composition based on farming practices data, a general linear model (GLM) was applied, using experiment as fixed factor and farming practices as covariates. A stepwise approach was used to identify significant covariates. The 
significance level was set to $P<0.05$. For each FA, proportion of different feedstuffs in the diet, altitude, milk yield, DIM, proportion of primiparous cows, and breed proportions in the herd were tested as covariates. All covariates were normally distributed. Data reported in percentages in surveys were divided by 100 to give a result ranging from 0 to 1 , and altitude was expressed as kilometers above sea level for model calculations. The linear, quadratic, and cubic effects of all the covariates were tested. The significant covariates were identified using only samples from on-farm experiments. To improve model reliability, samples from trials led in controlled conditions were then introduced into the calibration set to calculate model coefficients. The calibration models made it possible to predict the FA values of the validation set. The predicted versus measured regression values were used for the external validation of each model. Root mean square error (RMSE) and coefficient of determination were used to describe model fitting for both for calibration and external validation. Model fits were considered as good when the coefficient of determination was $\geq 0.50$ and very good when the coefficient of determination was $\geq 0.60$. Fisher's F-distribution of each variable included in a model was used as an indicator of the relative weight of the variable in determining the model itself.

As the proportion of fresh herbage in cow diet was expected to be the main covariate of most models, and as a large number of samples come from diets not including fresh herbage, the "overall" datasets were sorted into 2 subsets according to presence or absence of fresh herbage in the diet, giving a "fresh herbage" dataset (698 samples) and a "conserved forage" dataset (550 samples), respectively. To better understand the role of fresh herbage proportion in cow diets and to describe the influence of farming practices on milk FA composition when fresh herbage was not present in the cow diet, new models were developed on the resulting "fresh herbage" and "conserved forage" calibration datasets and compared to the "overall" one. External validation on the "fresh herbage" and "conserved forage" validation sets was also performed, using the procedure described above.

\section{RESULTS AND DISCUSSION}

\section{Dataset Variability}

Farming Practices. The average, minimum, and maximum for each parameter describing farming practices are reported in Table 2. Daily milk yield per cow ranged from very low values typical for dual-propose local breeds (Coppa et al., 2012a) to the high values of high-yielding, genetically selected breeds (Lechartier and Peyraud, 2010). Herd size varied from small herds (4 to 6 lactating cows) diffused in mountain areas (Agabriel et al., 2007) to large herds (up to 700 lactating cows) typical of intensive dairy farming systems (Stergiadis et al., 2012). Diet composition also varied strongly, from full fresh herbage or hay diets without concentrate supplementation to corn silage- or grass silage-based diets in which silage reached up to about $75 \%$ of DMI. Concentrates in cow diets ranged from 0 to about $60 \%$ of DMI. Diets presented by Stergiadis et al. (2012), Coppa et al. (2012b), Slots et al. (2009), and Butler et al. (2008) are included in the range of the present dataset. The altitude range $(0-2,000 \mathrm{~m}$ above sea level) was representative of farming systems located from lowland to upland Europe. Almost all the farming systems found in Europe are represented in this database.

Milk FA Composition. The average, minimum, and maximum for each FA or sums of FA are reported in Table 3. The range of variation in our dataset was similar to or smaller than that reported by Coppa et al. (2010) and Glasser et al. (2008). The smaller range found is not surprising, as the cited authors presented FA profiles of individual milks obtained in controlled conditions and included high-lipid-supplement diets. Concerning bulk milk from commercial farms, the range of variation found in the literature for all the studied FA were included within the ranges of our dataset for both moderate- or high-input dairy farms (Heck et al., 2009; Morales-Almaráz et al., 2011; Stergiadis et al., 2012) and extensive farms in upland regions (Collomb et al., 2008). The wide ranges found for short-chain FA (C4:0-C:10), especially C4:0, may be related to differences in analytical methods, as these FA are very volatile and the analytical method used can affect their apparent proportions in milk. In recent years, several techniques have been developed to reduce volatilization losses, but the older experiments were unable to benefit from these advances and strong differences between laboratories remain.

\section{Predicting Milk FA Composition, Based on Farming Practices: "Overall” Models}

The models for each studied FA are reported in Table 4. In general, the models were significant (data not shown) for all the studied FA, and the coefficients of determination found in calibration models were confirmed by the external validation for all FA. Models for each FA are discussed in the following paragraphs.

De Novo Preformed FA and SFA. De novosynthesized FA (C4:0-C14:0) concentrations increased as fresh herbage proportion in the cow diet decreased, and C8:0 to C12:0 concentrations increased as corn 
PREDICTING MILK FATTY ACIDS FROM FARMING PRACTICES

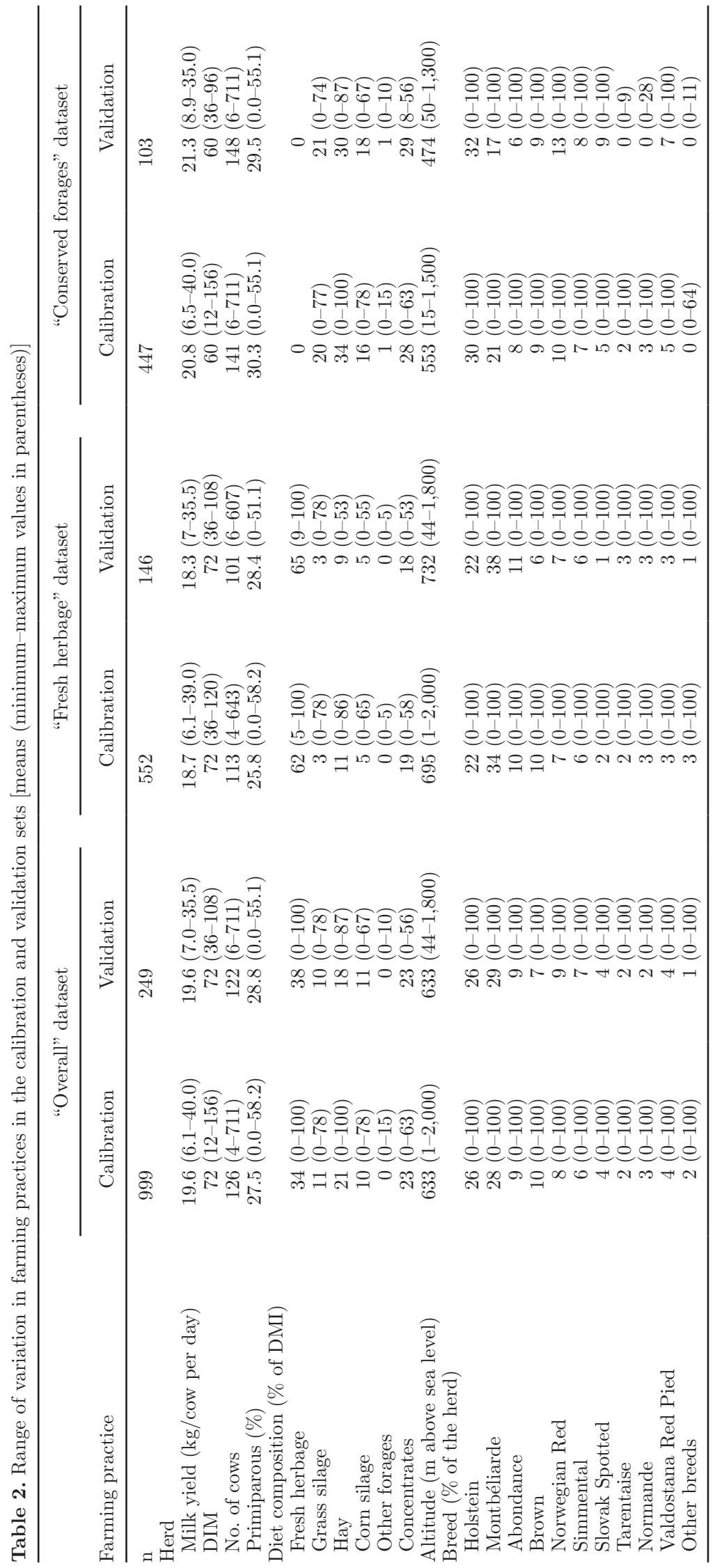


silage and concentrates increased. Increases in de novosynthesized FA have been related to high intakes of fermentable carbohydrates (Moate et al., 2008), possibly related to concentrate intake and composition. Increasing fresh herbage proportion in the diet also increased PUFA intake, which is known to partially inhibit de novo FA synthesis (Elgersma et al., 2006). Milk proportion of de novo-synthesized FA is also related to several other factors unavailable in the dataset, such as cow health, ruminal $\mathrm{pH}$ alteration, or milk fat depression (Griinari et al., 1998). For this reason, all the de novo-synthesized FA (except C4:0) could not be well predicted by models based on a simple description of cow diet. Moreover, the experiment effect showed a high Fisher's F-distribution for all short-chain de novosynthesized FA models (C4:0-C10:0). Given the high volatility of $\mathrm{C} 4: 0$, in its model, the experiment effect explained almost all the model variability (Fisher's F-distribution experiment vs. feedings: 119.0 vs. 46.3; Table 4), thus explaining the high coefficient of determination found for this FA.

The C16:0 concentration increased with concentrates and decreased with fresh herbage and grass silage proportions in cow diet. The coefficient of determination for C16:0 in the calibration and external validation models was higher than for the other de novo-synthesized FA (except for C4:0), probably due to the dual origin of C16:0, which is partially derived from dietary FA. The lower amount of C16:0 in milk from fresh herbage or grass silage feeding is a well-known trend (Dewhurst et al., 2006) and has been attributed to a lower C16:0 proportion in herbage than in corn silage (Elgersma et al., 2006). Some concentrates can be rich in C16:0 if they contain oilseed by-products (i.e., palm oil) as a lipid source (Chilliard et al., 2007).

The cis-9 C14:1 has been predicted by a model similar to C14:0, confirming that it was produced from C14:0 by $\Delta^{9}$-desaturase in the mammary gland (Chilliard et al., 2007). The cis-9 C14:1 decreased with increasing diet proportion of fresh herbage and decreasing hay proportion in the cow diet. However, predictions of cis-9 C14:1 were fairly poor $\left(\mathrm{R}^{2} \leq 0.25\right.$; Table 4$)$. This could be due to the low effect of cow diet (non-lipid supplemented) on $\Delta^{9}$-desaturase activity (Ferlay et al., 2006), which could also be the case for cis-9 C16:1 $\left(\mathrm{R}^{2} \leq 0.30\right)$.

The increase in milk SFA was well predicted by increases in all the conserved forages and concentrates in the cow diet $\left(R^{2} \geq 0.55\right.$ in both calibration and external validation models), confirming the high proportion of SFA found in milk from conserved forages and concentrate-rich diets (Dewhurst et al., 2006).

OCFA and BCFA. The C15:0, C17:0, and the OCFA increased with the increasing proportions of conserved grass (hay and grass silage) in the diet and decreased with increasing proportions of starch-rich feedstuffs (corn silage and concentrates). Odd-chain FA derive mainly from ruminal bacteria and can vary according to changes in ruminal flora composition (Vlaeminck et al., 2006). Increases in C15:0 and C17:0 proportions have been associated with a decrease in forage-to-concentrate ratio (Loor et al., 2005) and an increase in corn silage proportion (Vlaeminck et al., 2006).

Branched-chain FA, also derived from rumen microflora, were well predicted $\left(\mathrm{R}^{2} \geq 0.61\right)$ by an increase in fresh herbage and hay and a decrease in corn silage and concentrates in the cow diet (Table 4). This is consistent with the hypothesis that high-NDF diets (such as fresh herbage- and hay-based diets) favor ruminal populations of cellulolytic bacteria (rich in iso and anteiso FA) instead of the amylolytic bacteria (poor in iso and anteiso FA) favored by starch-rich diets (such as corn silage- and concentrate-based diets; Vlaeminck et al., 2006).

C18 FA and PUFA. Increasing fresh herbage and hay and decreasing corn silage and concentrates in the diet increased the milk $\mathrm{C} 18: 3 \mathrm{n}-3$ proportion $\left(\mathrm{R}^{2} \geq 0.66\right.$ in calibration and external validation models), in agreement with literature data (Couvreur et al., 2006; Ferlay et al., 2006). A high C18:3n-3 intake due to a high proportion of fresh herbage or hay (rich in this PUFA) could allow a fraction of the C18:3n-3 to escape biohydrogenation (Dewhurst et al., 2006). An inhibitory effect on the activity or number of rumen microflora responsible for ruminal PUFA biohydrogenation could also be induced by plant secondary metabolites, which are abundant in the dicotyledonous species found in permanent grasslands (Collomb et al., 2002; Leiber et al., 2005).

Milk C18:2n-6 proportion increased with increasing corn silage and concentrate proportions in the diet. The C18:2n-6 is already an indicator of corn silage-based diets, as corn is rich in this FA (Ferlay et al., 2008; Slots et al., 2009). Furthermore, milk C18:2n-6 proportion decreased with increasing proportions of conserved herbage (hay and grass silage) in the diet, confirming similar results found by Sterk et al. (2011). Even so, the prediction was relatively poor $\left(\mathrm{R}^{2} \leq 0.40\right)$, possibly due to the multiple dietary sources of C18:2n-6 in the cow diet that could interact to precisely shape milk C18:2n-6 proportion. Indeed, soybean and sunflower supplements are also important sources of C18:2n-6, increasing its proportions in milk (Chilliard et al., 2007; Glasser et al., 2008), even in fresh herbage- or conserved herbage-based diets. Furthermore, the greater presence of secondary metabolite-rich plant species in upland grasslands could also explain the increase in milk C18:2n-6 at higher altitude found in our model. 


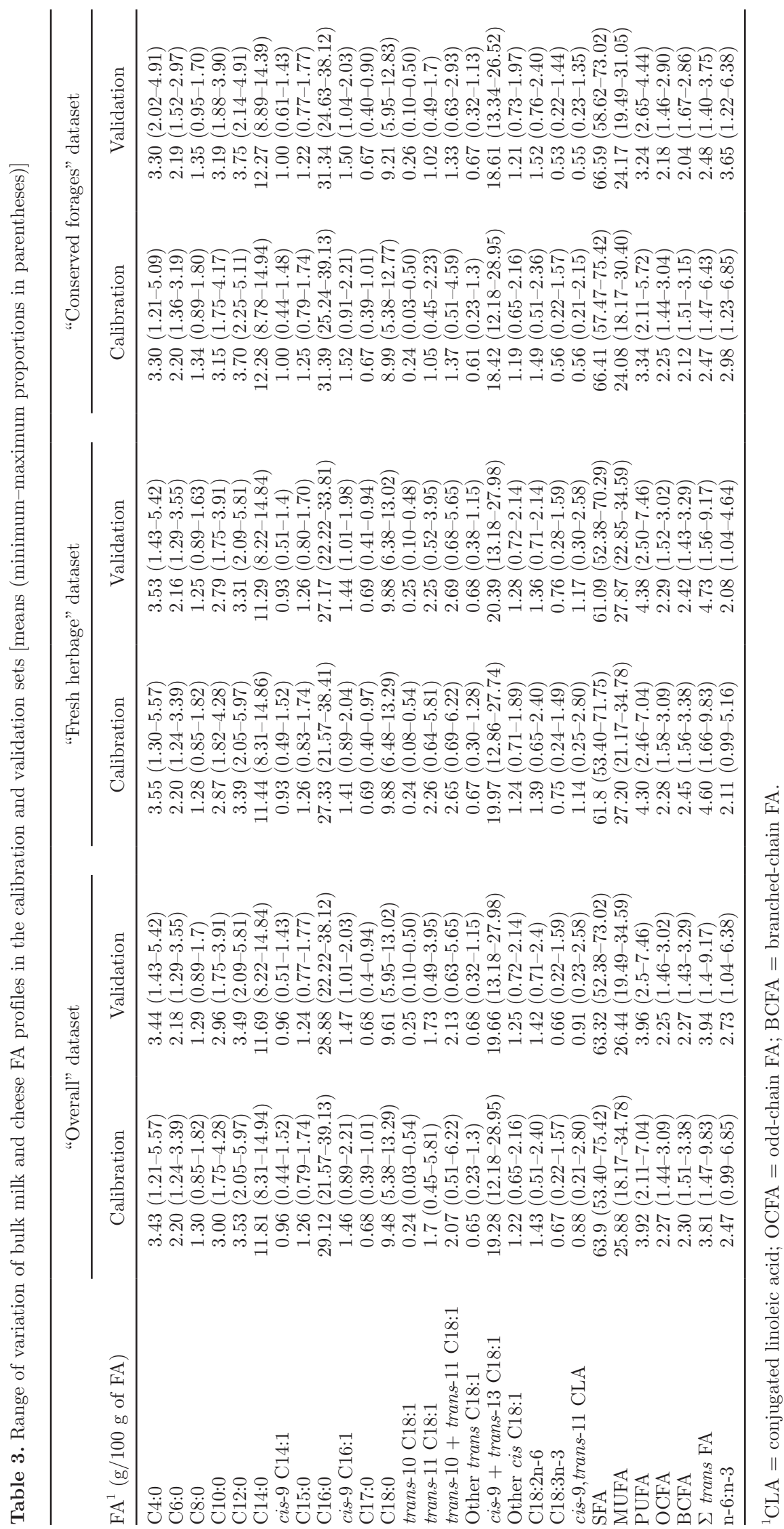




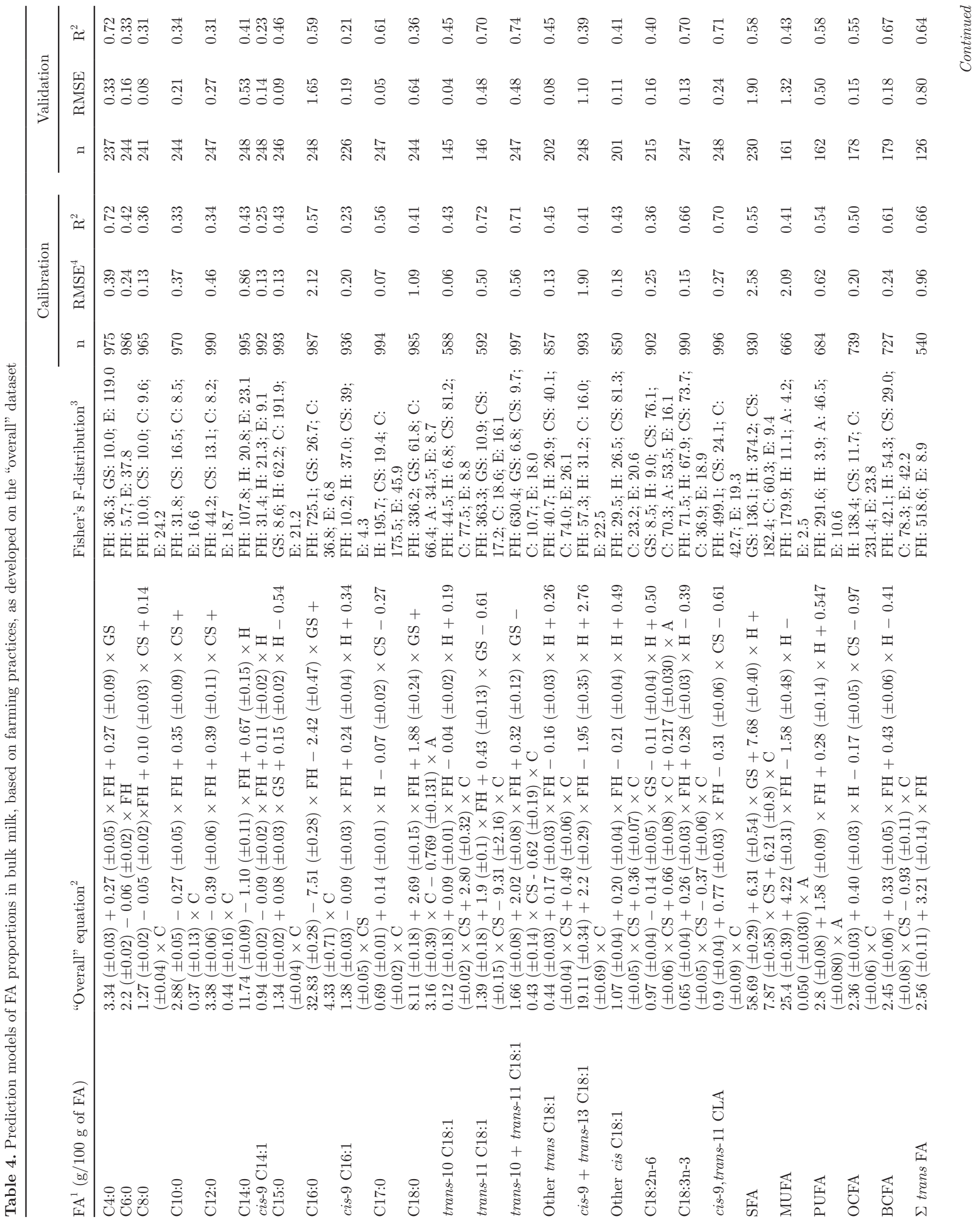


The decrease in milk PUFA and n-6:n-3 ratio with decreasing fresh herbage or hay proportions in the cow $\operatorname{diet}\left(R^{2} \geq 0.54\right.$ and $R^{2} \geq 0.67$, respectively; Table 4$)$ is in agreement with the higher n-3 PUFA and relatively lower n-6 intake with these diets (Ferlay et al., 2006; Slots et al., 2009) and with all the hypotheses presented for C18:2n-6 and C18:3n-3 models.

The increase in trans-11 C18:1 and trans-10+ trans-11 C18:1 proportions with increasing proportion of fresh herbage and grass silage and decreasing proportion of corn silage and concentrates $\left(\mathrm{R}^{2} \geq 0.70\right)$ are in agreement with literature data (Couvreur et al., 2006; Sterk et al., 2011). The major isomer of the trans-10 + trans-11 C18:1 sum, trans-11 C18:1, is in fact the main intermediate product of the ruminal biohydrogenation of dietary PUFA ingested by cows, particularly the C18:3n-3 found in fresh herbage (Dewhurst et al., 2006; Elgersma et al., 2006). A similar and good prediction model $\left(\mathrm{R}^{2} \geq 0.70\right.$ : Table 4) was found for cis-9,trans-11 CLA, which is mainly produced from trans-11 C18:1 by $\Delta^{9}$-desaturase in the mammary gland (Griinari et al., 1998). High correlations between these two FA were also found by Ferlay et al. (2008), and explained by their common origin. The sum of trans FA increased with increasing fresh herbage proportion in the diet, which is also the main covariate in the models of the major trans isomers included in the sum of trans FA: trans-10 + trans-11 C18:1 and cis-9,trans-11 CLA.

The trans-10 C18:1 and the other trans C18:1 isomer concentrations increased with increasing C18:2n-6 and starch sources in the diet. A positive relationship was found with corn silage and concentrate proportions in the cow diet (Table 4). The trans-10 C18:1 and the other trans $\mathrm{C} 18: 1$ isomers are mainly derived from alternative rumen biohydrogenation pathways of C18:2n- 6 (Colman et al., 2010). The shift from trans-11 to other trans C18:1 biohydrogenation pathways could depend on alteration of ruminal microflora following the $\mathrm{pH}$ alteration (Griinari et al., 1998) caused by starch- and (or) corn-rich diets. This shift mainly concerns trans-10 C18:1, although Colman et al. (2010) also found higher proportions of other C18:1 isomers and suggested that similar considerations could be made for other cis C18:1 isomers.

Milk C18:0 proportion increased with increasing fresh herbage, grass silage, and concentrate proportions in the diet, and decreased with altitude. The C18:0 predictions were fairly poor $\left(\mathrm{R}^{2} \leq 0.41\right)$, probably due to the multiple processes determining its proportion in milk. As C18:0 is the final product of dietary PUFA biohydrogenation, it could be affected by type of concentrates or by plant secondary metabolites, and may be partially $\Delta^{9}$-desaturated into cis-9 $\mathrm{C} 18: 1$ in the mammary gland (Leiber et al., 2005; Chilliard et al., 


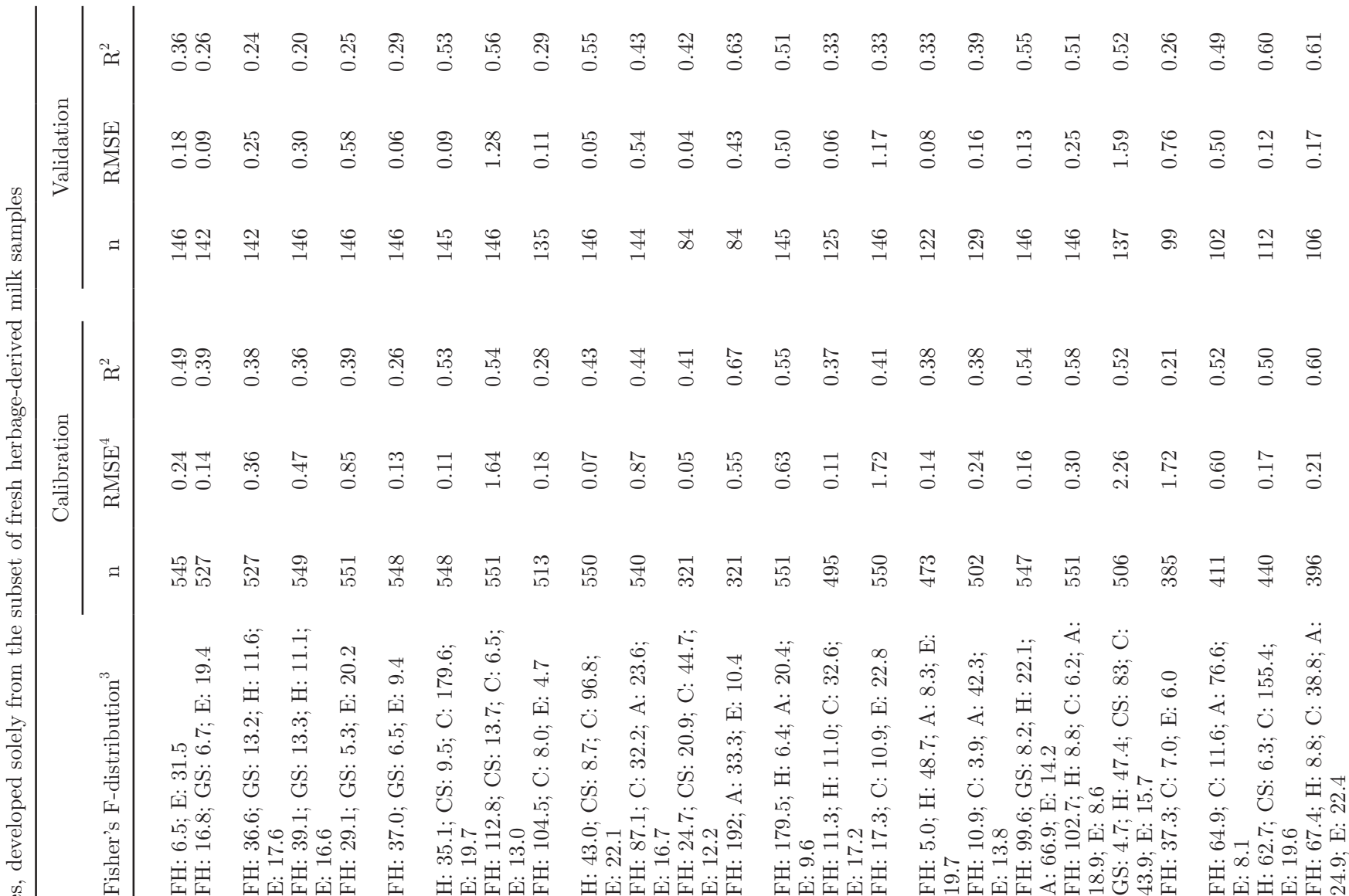

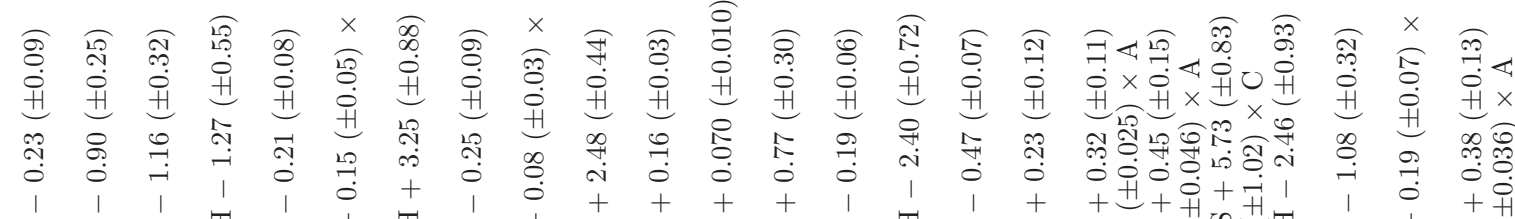

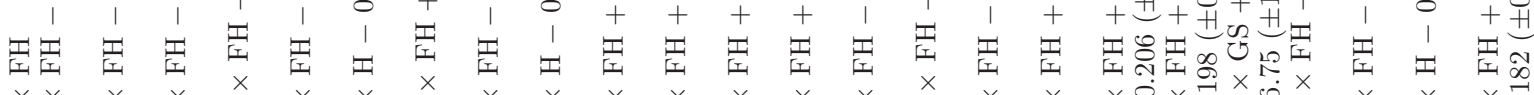

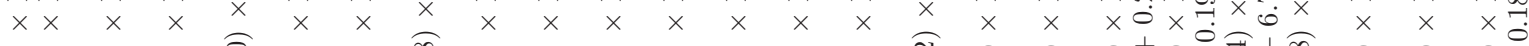

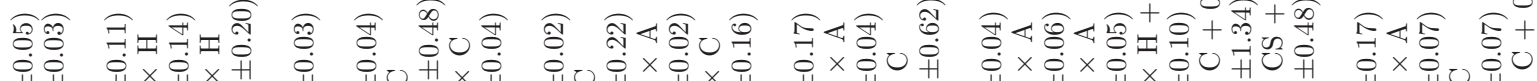

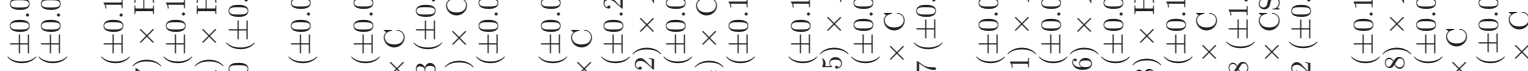
m 9 o

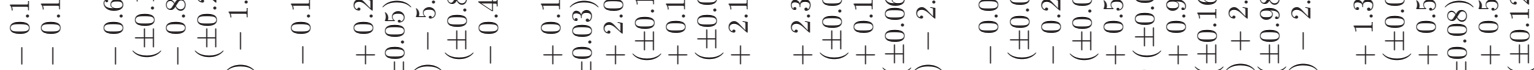

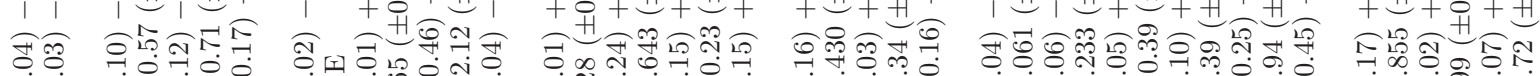

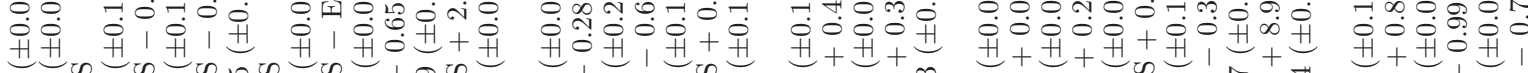

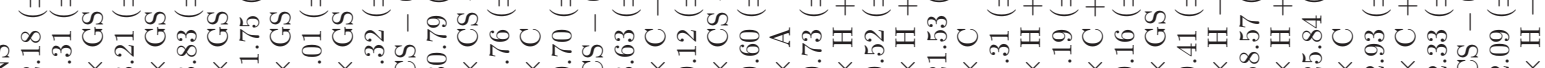


2007). A similar hypothesis could also explain the low model fit of cis-9 + trans-13 C18:1 $\left(\mathrm{R}^{2}<0.41\right)$. In part dietary derived (Chilliard et al., 2007), cis-9 C18:1 increased with increasing proportion of fresh herbage and concentrate and decreased with increasing proportion of hay. Its proportion in milk may also be dependent on pasture type and phenology (Tornambé et al., 2010b; Coppa et al., 2011a) and on lipomobilization of body fat reserves (Chilliard et al., 2007).

Evaluation of the Applied Methodology. Using simple information on farming practices to predict the main milk FA proportions is a promising strategy. Almost all milk FA of nutritional interest were well fitted by the models presented in this paper. Average milk yield, DIM, proportion of primiparous cows, and breed composition of the herd had no significant effects in any of the FA models, thus were negligible in on-farm conditions. On the contrary, the effects of diet composition and altitude significantly contributed to model calibration, confirming their major importance in determining milk FA proportions. Quadratic or cubic effects were never significant for any of the variables. Our results, obtained on a huge dataset of commercial milk samples, confirmed literature data from experiments in strictly controlled conditions [for reviews, see Dewhurst et al. (2006) and Chilliard et al. (2007)]. Given that uncontrolled on-farm factors unrelated to farm practices can increase the variability of results and, thus, the residual error of the models, our results emerge as even more robust. However, the survey approach used to collect farming practices data could imply approximations and lower detail in information compared with controlled experiments (i.e., we had to pool together all the concentrates, regardless of type or source). This is particularly the case for fresh herbage proportion in the cow diet, which was the main explanatory covariate in almost all the FA models. Estimating fresh herbage intake by grazing herds at pasture on commercial farms remains a challenge, and the hypothesis used here (energy balance equal to zero or grass fed ad libitum to complete the potential intake capacity) could also have decreased the precision of the estimation. This is proven by the RMSE, which remained quite high even for those FA that were well fitted by the models. Nevertheless, our model appeared to have a lower RMSE than those developed by Glasser et al. (2008), probably due to the low number of milk samples in their datasets compared with ours. As Glasser et al. (2008) focused their models on the effect of oilseed supplements on milk fat composition, their wider range of FA profiles compared with our FA dataset could explain the better model fits found by those authors. The RMSE found here were similar or just slightly lower than those found by Sterk et al. (2011), who developed models in a con- 


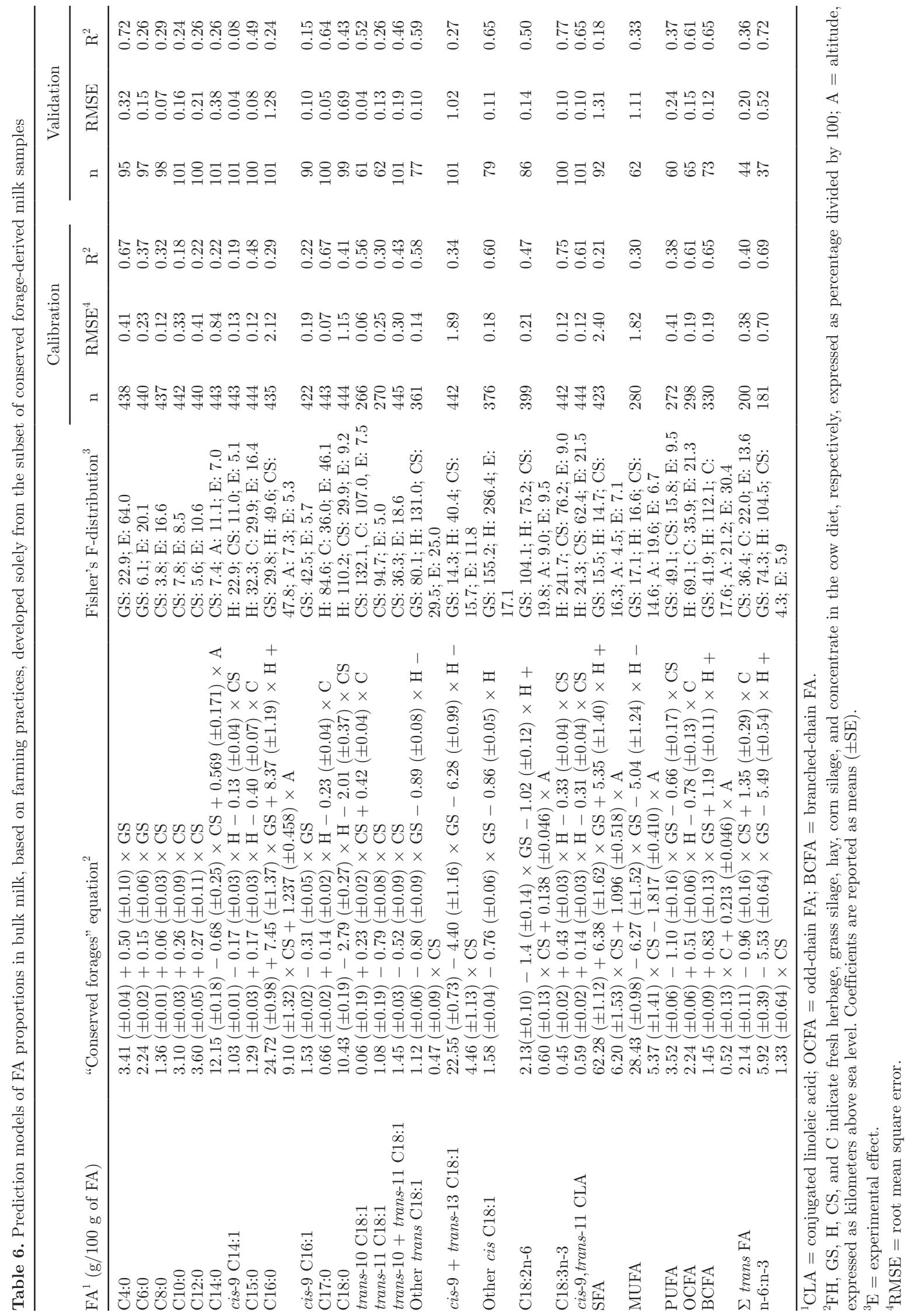


trolled trial on individual milks, thus further confirming the reliability of our results.

\section{“Overall” vs. "Fresh Herbage” Models}

As shown in the "overall" dataset models, the proportion of fresh herbage in the diet remained the most explanatory covariate of almost all the models calibrated on the "fresh herbage" dataset, being the most commonly present and generally having a high Fisher's F-distribution (Table 5). Similarly, it remained nonsignificant for C15:0, C17:0, OCFA, and SFA (Table 5). Furthermore, when "overall" models were compared with "fresh herbage" models, the proportion of corn silage lost its significance for several FA, and was replaced by grass silage and (or) hay proportion in all the de novo-synthesized FA trans-10 + trans-11 C18:1, C18:3n-3, and cis-9,trans-11 CLA models. The proportion of corn silage in the diet was also replaced by altitude for the models of $\mathrm{C} 18: 3 \mathrm{n}-3$ and all intermediates of ruminal biohydrogenation (trans-11 C18:1, trans-10 + trans-11 C18:1, other trans $\mathrm{C} 18: 1$, other cis C18:1, C18:3n-3, and cis-9,trans-11 CLA), possibly for the same reason as illustrated for the PUFA models built on the "overall" dataset. Higher BCFA proportions with increasing altitude is consistent with Engel et al. (2007) who found higher proportions of these FA in milk produced on upland regions. Altitude is usually associated with more extensively managed pastures that are characterized by a lower regrowth potential. Thus, to obtain an optimum use of biomass production, farmers are encouraged to use forage resources at advanced phenological stages. The high fiber proportion of mature herbage is known to favor rumen cellulolytic bacteria, whose membrane lipids are BCFA rich (Vlaeminck et al. 2006), resulting in higher milk fat BCFA proportions (Coppa et al., 2011a).

When models developed on the "overall" dataset were tested against models calibrated on the "fresh herbage" dataset, we observed a decrease in coefficient of determination values (Tables 4 and 5). Fresh herbagederived milk is characterized by the lowest SFA and C18:2n-6 proportions and the highest trans-11 C18:1, cis-9,trans-11 CLA, C18:3n-3, and BCFA proportions (Ferlay et al., 2008; Slots et al., 2009). Consequently, "fresh herbage" models were built on a reduced range of FA proportions and a lower number of samples, resulting in lower model fits compared with the "overall" models. On the other hand, reducing the range of variation of some FA also reduced the RMSE in both the calibration and validation "fresh herbage" models, as was the case for C16:0, C18:0, cis-9 + trans-13 C18:1, SFA, MUFA, and $\Sigma$ n- $6: \Sigma$ n-3 ratio. According to these considerations, the "overall" models appear equally as reliable as the "fresh herbage" model for predicting milk FA profile, based on farming practices when cows are fed fresh herbage.

\section{“Overall” vs. "Conserved Forages" Models}

When the "conserved forages" models were compared with the "overall" models, a strong decrease was observed in model fit $\left(\mathrm{R}^{2}\right)$ for several FA (i.e., C16:0, trans-11 C18:1, trans-10 + trans-11 C18:1, cis-9,trans-11 CLA, SFA, PUFA, and the sum of trans FA; Table 6). No main covariates of the models could be found among the conserved forages: proportions of grass silage, hay, and corn silage in the diet all had Fisher's F-distribution values that were closer than those observed for fresh herbage or all the other feedstuffs in the "overall" and "fresh herbage" models (Tables 4, 5, and 6). Concentrate proportion lost its significance in almost all "conserved forages" models compared with "overall" or "fresh herbage" models. It had a slight but significant effect for C15:0, C17:0, OCFA, and BCFA models only. This decrease in significance of concentrate proportion in the diet on milk FA could be related to a greater effect of type of forage and concentrate rather than of quantity in conserved forage-based diets (Lechartier and Peyraud, 2010).

The quality of the model's fit was maintained for BCFA and n-6:n-3 ratio ( $\mathrm{R}^{2}$ similar to and RMSE similar to or lower than the "overall" models) and improved for C15:0, C17:0, OCFA, trans-10 C18:1, other trans C18:1, other cis C18:1, C18:2n-6, and C18:3n-3 $\left(\mathrm{R}^{2}\right.$ higher than in the "overall" models). Thus, the "conserved forage" models for these FA appear more reliable than the "overall" models for predicting milk FA composition, based on farming practices when cows are not fed fresh herbage.

The C15:0, C17:0, and OCFA proportions increased with increasing proportion of hay in the diet and decreased with increasing proportion of concentrate (Table 6), in agreement with the hypothesis discussed for the "overall" models. The trans-10 C18:1 increased with increasing the starch source and C18:2n-6 sources in the diet (corn silage and concentrates), in agreement with Griinari et al. (1998). Proportions of other trans C18:1 isomers decreased with increasing proportion of conserved forage (grass silage, hay, or corn silage) in the diet $\left(\mathrm{R}^{2} \geq 0.52\right)$, confirming the effect of high-forage diets on the formation of trans-11 C18:1 instead of the other trans C18:1 isomers in the rumen (Colman et al., 2010). The C18:2n-6 proportion decreased with increasing proportion of conserved grass (hay or silage) and increased with increasing corn silage and altitude, as found in the "overall" model, but the proportion of concentrate lost its significance. The higher fit of 
the "conserved forage" model could be related to the absence of fresh herbage, for which C18:2n-6 proportion in milk can vary strongly according to herbage phenology and botanical composition (Tornambé et al., 2010a; Coppa et al., 2011a). Milk C18:3n-3 proportion increased with increasing proportion of hay in the diet but decreased with increasing proportion of corn silage $\left(\mathrm{R}^{2} \geq 0.70\right)$, confirming that hay-derived milk fat is rich in C18:3n-3, especially when the hay is artificially dried or from upland grasslands (Dewhurst et al., 2006; Chilliard et al., 2007; Baars et al., 2012).

\section{CONCLUSIONS}

Our work provided original models to predict the FA profile of bulk milk, based on farming practices collected via on-farm surveys. A European scale dataset was used. Good prediction models were found for several FA (i.e., trans-11 C18:1, trans-10 + trans-11 C18:1, cis-9,trans-11 CLA, total trans FA, C18:3n-3, n-6:n-3 ratio, and BCFA). Proportion of fresh herbage in the cow diet was the main covariate in almost all the FA models. Models calibrated using only a subset of samples derived from conserved forages also gave good predictions for OCFA, trans-10 C18:1, the other cis and trans C18:1, C18:2n-6, and C18:3n-3, which were more reliably predicted than by models also including fresh herbage-derived milk data. Models calibrated on the "overall" dataset were more reliable for all the other FA. The large range of our dataset and the quality of the predictions highlighted the robustness of the cow feed effect on milk FA profile found in controlled conditions compared with animal-related factors (such as breed, DIM, and milk yield) that seem to be negligible at farm scale. These prediction models could offer a valuable tool to help farmers improve the proportion of health-promoting FA in milk fat.

\section{ACKNOWLEDGMENTS}

This work was supported by the INRA-PHASE division that funded M. Coppa's postdoctoral fellowship at the INRA-UMRH unit (Clermont-Ferrand, France).

\section{REFERENCES}

Agabriel, C., A. Cornu, C. Journal, C. Sibra, P. Grolier, and B. Martin. 2007. Tanker milk variability according to farm feeding practices: Vitamins A and E, carotenoids, color, and terpenoids. J. Dairy Sci. 90:4884-4896.

Baars, T., J. Wohlers, D. Kusche, and G. Jahreis. 2012. Experimental improvement of cow milk fatty acid composition in organic winter diets. J. Sci. Food Agric. 92:2883-2890.

Butler, G., J. H. Nielsen, T. Slots, C. Seal, M. D. Eyre, R. Sanderson, and C. Leifert. 2008. Fatty acid and fat-soluble antioxidant concentrations in milk from high- and low-input conventional and organic systems: Seasonal variation. J. Sci. Food Agric. 88:1431-1441.
Chilliard, Y., F. Glasser, A. Ferlay, L. Bernard, J. Rouel, and M. Doreau. 2007. Diet, rumen biohydrogenation and nutritional quality of cow and goat milk fat. Eur. J. Lipid Sci. Technol. 109:828855.

Collomb, M., W. Bisig, U. Bütikofer, R. Sieber, M. Bregy, and L. Etter. 2008. Fatty acid composition of mountain milk from Switzerland: comparison of organic and integrated farming systems. Int. Dairy J. 18:976-982.

Collomb, M., U. Bütikofer, R. Sieber, B. Jeangros, and J.-O. Bosset. 2002. Correlations between fatty acids in cows' milk fat produced in the lowland, mountain and highlands of Switzerland and botanical composition of the fodder. Int. Dairy J. 12:661-666.

Colman, E., W. B. Fokkink, M. Craninx, J. R. Newbold, B. De Baets, and V. Fievez. 2010. Effect of introduction of subacute ruminal acidosis on milk fat profile and rumen parameters. J. Dairy Sci. 93:4759-4773.

Coppa, M., A. Ferlay, C. Leroux, M. Jestin, Y. Chilliard, B. Martin, and D. Andueza. 2010. Prediction of milk fatty acid composition by near infrared reflectance spectroscopy. Int. Dairy J. 20:182189.

Coppa, M., A. Ferlay, F. Monsallier, I. Verdier-Metz, P. Pradel, R. Didienne, A. Farruggia, M. C. Montel, and B. Martin. 2011a. Milk fatty acid composition and cheese texture and appearance from cows fed hay or different grazing systems on upland pastures. J. Dairy Sci. 94:1132-1145.

Coppa, M., A. Gorlier, M. Lonati, B. Martin, E. M. Russo, and G. Lombardi. 2012a. The management of the transition from hay- to pasture-based diets affects milk fatty acid kinetics. Dairy Sci. Technol. 92:279-295.

Coppa, M., B. Martin, C. Agabriel, C. Chassaing, C. Sibra, I. Constant, B. Graulet, and D. Andueza. 2012b. Authentication of cow feeding and geographic origin on milk using visible and near-infrared spectroscopy. J. Dairy Sci. 95:5544-5551. http://dx.doi. org/10.3168/jds.2011-5272.

Coppa, M., I. Verdier-Metz, A. Ferlay, P. Pradel, R. Didienne, A. Farruggia, M. C. Montel, and B. Martin. 2011b. Effect of different grazing systems on upland pastures compared with hay diet on cheese sensory properties evaluated at different ripening times. Int. Dairy J. 21:815-822.

Couvreur, S., C. Hurtaud, C. Lopez, L. Delaby, and J. L. Peyraud. 2006. The linear relationship between the proportion of fresh grass in the cow diet, milk fatty acid composition, and butter properties. J. Dairy Sci. 89:1956-1969.

Dawczynski, C., L. Martin, A. Wagner, and G. Jahreis. 2010. n-3 LC-PUFA-enriched dairy products are able to reduce cardiovascular risk factors: A double-blind, cross-over study. Clin. Nutr. $29: 592-599$

De Noni, I., and G. Battelli. 2008. Terpenes and fatty acid profiles of milk fat and "Bitto" cheese as affected by transhumance of cows on different mountain pastures. Food Chem. 109:299-309.

Dewhurst, R. J., K. J. Shingfield, M. R. F. Lee, and N. D. Scollan. 2006. Increasing the concentrations of beneficial polyunsaturated fatty acids in milk produced by dairy cows in high-forage systems. Anim. Feed Sci. Technol. 131:168-206.

Elgersma, A., S. Tamminga, and G. Ellen. 2006. Modifying milk composition through forage. Anim. Feed Sci. Technol. 131:207-225.

Engel, E., A. Ferlay, A. Cornu, Y. Chilliard, C. Agabriel, G. Bielicki, and B. Martin. 2007. Relevance of isotopic and molecular biomarkers for the authentication of milk according to production zone and type of feeding. J. Agric. Food Chem. 55:9099-9108.

FAO (Food and Agriculture Organization of the United Nations). 2012. Statistical dataset. Accessed Sep. 2012. http://faostat.fao. org/site/610/DesktopDefault.aspx?PageID $=610 \#$ ancor

Faverdin, P., R. Delagarde, L. Delaby, and F. Mechy. 2007. Alimentation des vaches laitières. Pages 23-55 in Alimentation des bovins, ovins et caprins. Besoins des animaux-Valeurs des aliments. Tables INRA 2007. Quae éditions, Versailles, France.

Ferlay, A., C. Agabriel, C. Sibra, C. Journal, B. Martin, and Y. Chilliard. 2008. Tanker milk variability in fatty acids according to farm feeding and husbandry practices in a French semi-mountain area. Dairy Sci. Technol. 88:193-215. 
Ferlay, A., B. Martin, P. Pradel, J. B. Coulon, and Y. Chilliard. 2006. Influence of grass-based diets on milk fatty acid composition and milk lipolytic system in Tarentaise and Montbéliarde cow breeds. J. Dairy Sci. 89:4026-4041.

Givens, D. I. 2010. Milk and meat in our diet: Good or bad for health? Animal 4:1941-1952.

Glasser, F., A. Ferlay, and Y. Chilliard. 2008. Oilseed lipid supplement and fatty acid composition of cow milk: A meta-analysis. J. Dairy Sci. 91:4687-4703.

Griinari, J. M., D. A. Dwyer, M. A. McGuire, D. E. Bauman, D. L. Palmquist, and K. V. V. Nurmela. 1998. Trans-octadecenoic acids and milk fat depression in lactating dairy cows. J. Dairy Sci. 81:1251-1261.

Heck, J. M. L., H. J. F. van Valenberg, J. Dijkstra, and A. C. M. van Hooijdonk. 2009. Seasonal variation in the Dutch bovine raw milk composition. J. Dairy Sci. 92:4745-4755.

ISO (International Organization for Standardization). 2000. Animal and vegetable fats and oils-Preparation of methyl esters of fatty acids, Clause 5: Transesterification method. ISO Standard 5509:2000. ISO, Geneva, Switzerland.

Kratz, M., T. Baars, and S. Guyenet. 2013. The relationship between high-fat dairy consumption and obesity, cardiovascular, and metabolic disease. Eur. J. Nutr. 52:1-24. http://dx.doi.org/10.1007/ s00394-012-0418-1.

Kusche, D., K. Rubesam, and T. Baars. 2010. Fatty acid and antioxidant profiles in summer milk from different biodynamic and conventional systems in Southern Germany. Pages 604-606 in Grassland in a Changing World. Grassland Science in Europe. Vol. 15. H. Schnyder, J. Isselstein, E. Taube, K. Auerswald, J. Schellberg, M. Wachendorf, A. Herrmann, M. Gierus, N. Wrage, and A. Hopkins, ed. Universität Göttingen, Göttingen, Germany.

Lechartier, C., and J.-L. Peyraud. 2010. The effects of forage proportion and rapidly degradable dry matter from concentrate on ruminal digestion in dairy cows fed corn silage-based diets with fixed neutral detergent fiber and starch contents. J. Dairy Sci. 93:666-681.

Leiber, F., M. Kreuzer, D. Nigg, H.-R. Wettstein, and M. R. L. Scheeder. 2005. A study on the causes for the elevated n-3 fatty acids in cows' milk of Alpine origin. Lipids 40:191-202.

Loor, J. J., A. Ferlay, A. Ollier, M. Doreau, and Y. Chilliard. 2005. Relationship among trans and conjugated fatty acids and bovine milk fat yield due to dietary concentrate and linseed oil. J. Dairy Sci. 88:726-740.

Lucas, A., C. Agabriel, B. Martin, A. Ferlay, I. Verdier-Metz, J.-B. Coulon, and E. Rock. 2006a. Relationships between the conditions of cow's milk production and the contents of components of nutritional interest in raw milk farmhouse cheese. Lait 86:177-202.

Lucas, A., E. Rock, J.-F. Chamba, I. Verdier-Metz, P. Bracket, and J.-B. Coulon. 2006b. Respective effects of milk composition and the cheese-making process on cheese compositional variability in components of nutritional interest. Lait 86:21-41.

Moate, P. J., W. Chalupa, R. C. Boston, and I. J. Lean. 2008. Milk fatty acids II: Prediction of the production of individual fatty acids in bovine milk. J. Dairy Sci. 91:1175-1188.

Moioli, B., G. Contarini, L. Pariset, C. Marchitelli, A. Crisà, G. Catillo, and F. Napolitano. 2012. Genetic variation of C18:1 and C18:2 isomers in sheep milk fat. Small Rumin. Res. 103:187-193.

Morales-Almaráz, E., B. de la Roza-Delgado, A. González, A. Soldado, M. L. Rodríguez, M. Peláez, and F. Vicente. 2011. Effect of feed- ing system on unsaturated fatty acid level in milk of dairy cows. Renewable Agric. Food Syst. 26:224-229.

Palmquist, D. L., A. D. Beaulieu, and D. M. Barbano. 1993. Feed and animal factors influencing milk fat composition. J. Dairy Sci. 76:1753-1771.

Revello Chion, A., G. Battelli, D. Giaccone, P. G. Peiretti, E. Tabacco, and G. Borreani. 2010a. Seasonal variation of fatty acid in milk of intensive and extensive dairy system in Northern Italy. Pages 613615 in Grassland in a Changing World. Grassland Science in Europe. Vol. 15. H. Schnyder, J. Isselstein, E. Taube, K. Auerswald, J. Schellberg, M. Wachendorf, A. Herrmann, M. Gierus, N. Wrage, and A. Hopkins, ed. Universität Göttingen: Göttingen, Germany.

Revello Chion, A., E. Tabacco, G. Battelli, F. Righi, A. Quarantelli, D. Giaccone, and G. Borreani. 2012. Effects of fresh forage inclusion in diet of high performance dairy cows on milk production and composition. Pages 405-407 in Grassland-A European Resource? Grassland Science in Europe. Vol. 17. P. Goliński, M. Warda, and P. Stypiński, ed. Polish Grassland Society, Lublin, Poland.

Revello Chion, A., E. Tabacco, D. Giaccone, P. G. Peiretti, G. Battelli, and G. Borreani. 2010b. Variation of fatty acid and terpene profile in mountain milk and "Toma Piemontese" cheese as affected by diet composition in different seasons. Food Chem. 121:393-399.

Slots, T., G. Butler, C. Leifert, T. Kristensen, L. H. Skibsted, and J. H. Nielsen. 2009. Potentials to differentiate milk composition by different feeding strategies. J. Dairy Sci. 92:2057-2066.

Stergiadis, S., C. Leifert, C. J. Seal, M. D. Eyre, J. H. Nielsen, M. K. Larsen, T. Slots, H. Steinshamn, and G. Butler. 2012. Effect of feeding intensity and milking system on nutritionally relevant milk components in dairy farming systems in the north east of England. J. Agric. Food Chem. 60:7270-7281.

Sterk, A., B. E. O. Johansson, H. Z. H. Taweel, M. Murphy, A. M. van Vuuren, W. H. Hendriks, and J. Dijkstra. 2011. Effects of forage type, forage to concentrate ratio, and crushed linseed supplementation on milk fatty acid profile in lactating dairy cows. J. Dairy Sci. 94:6078-6091.

Tornambé, G., A. Ferlay, A. Farruggia, Y. Chilliard, P. Loiseau, P. Pradel, B. Graulet, B. Chaveau-Duriot, and B. Martin. 2010a. Influence of botanical diversity and development stage of mountain pastures on milk fatty acid composition, carotenoids, fat-soluble vitamins and sensory properties. Pages 589-591 in Grassland in a Changing World. Grassland Science in Europe. Vol. 15. H. Schnyder, J. Isselstein, E. Taube, K. Auerswald, J. Schellberg, M. Wachendorf, A. Herrmann, M. Gierus, N. Wrage, and A. Hopkins, ed. Universität Göttingen, Göttingen, Germany.

Tornambé, G., B. Martin, P. Pradel, A. Di Grigoli, A. Bonanno, Y. Chilliard, and A. Ferlay. 2010b. The maturity stage of the grass affects milk fatty acids of cow grazing mountain grassland. Pages 628-629 in Grassland in a Changing World. Grassland Science in Europe. Vol. 15. H. Schnyder, J. Isselstein, E. Taube, K. Auerswald, J. Schellberg, M. Wachendorf, A. Herrmann, M. Gierus, N. Wrage, and A. Hopkins, ed. Universität Göttingen, Göttingen, Germany.

Vlaeminck, B., V. Fievez, A. R. J. Cabrita, A. J. M. Fonseca, and R. J. Dewhurst. 2006. Factors affecting odd- and branched-chain fatty acids in milk: A review. Anim. Feed Sci. Technol. 131:389-417.

World Health Organization. 2008. Interim summary of conclusions and dietary recommendations on total fat and fatty acids. Accessed Sep. 2012. http://www.who.int/nutrition/topics/FFA_summary_ rec_conclusion.pdf. 